folium, Geranium, Sedum, \&c. The forests which clothe the banks of the Jenissei consist to a great extent of nonScandinavian trees, namely, of the larch, Pinzes cembra, Abies sibirica, and the Abies obovate, which scarcely differs from Pinus abies, and of Populus nigra. Of the trees common to Scandinavia the most important are the birch (Betula verrucosa and glutinosa), pine, aspen, bird's cherry, and mountain ash. Besides, the Salices play a very important part on the Jenissei, inasmuch as they form extensive woods on the low banks periodically overflowed; these Salices often grow to uncommonly large sizes, and consist in part of non-Scandinavian species, one of which, Salix vitellina, is the most common of all, and spreads over the whole of the region examined by the botanists of the expedition.

The bush vegetation too in Siberia exhibits differences from that of Scandinavia. On the Jenissei Alnaster fruiticosies is important beyond others, because it forms thickets, and especially towards the north increases in mass, going in that direction beyond the limit of trees. Among other bushes foreign to our flora there occur on the Jenissei the Siberian pea tree (Robinia), Spirce confusa, sorbifolia and salicifolia, Sambucus racemosa, Cratagus sanguined, Cassandra calyculato, peculiar types of roses, \&c. Among the bushes common to Scandinavia the most important are the black and red currant, dwarf birch, Lonicera corulea, which is far more widely distributed than in Sweden, juniper, Myrica gale, raspberry, Empetrum nigrum, Vaccinium vitis idac, and myrtillus, \&c. Towards the north the bushy Salices play an important part, as in our northern regions. On the Jenissei there has been found only one species of $A$ lnzks, which is specially interesting as not being either of the Swedish species, but perhaps the genuine Alnuts pubescens. On the other hand there are absent on the Jenissei many of our trees and bushes, as the nobler deciduous trees and fruit trees, and, what may be said to be distinctive of the Jenissei flora, heather, which is so extensively distributed in Sweden, is wanting.

\section{TEMPERATURE AND HUMIDITY OF THE} AIR AT DIFFERENT HEIGHTS

$A$ MEMOIR on the temperature and humidity A of the air at different hours, by Dr. H. E. Hamberg, based on observations made by him during the summer of 1875 , at heights varying from 2 inches to 22 feet above the ground, was published recently in the Transactions of the Royal Society of Sciences at Upsal. The memoir is a valuable one, and is of interest to more than the mere meteorologist, it being evident that the inquiry is so handled as to bring it into close connection with such difficult questions as convection currents in the free atmosphere and the diffusion of vapour through the air.

In clear weather the temperature of the air nearest the surface was lower than that above it, from two to three hours before sunset to at least two to three hours after sunrise. At all the six heights the temperature fell to the minimum at the same hour, viz., about 3 A.M. ; but while it continued from this time to rise steadily at all the heights, the lowest temperatures continued to be observed in the strata nearest the ground till several hours after sunrise. From this remarkable result Dr. Hamberg concludes that the increase of temperature in the lower strata of the air in the early part of the forenoon is not an immediate and direct consequence of the heating of the ground, but is rather to be attributed to the absorption by the air, or more strictly by its aqueous vapour, of the heat received from the sun's rays or reflected from the ground.

Over uneven ground covered with vegetation the temperature near the surface is generally higher over those parts of the field which rise above the general level. Thus even slight elevations of only one or two feet have the air immediately resting on them often $2^{\circ}$ higher or mure, whilst on the other hand, a trench or depression one or two feet below the general level has the air resting on it often $2^{\circ}$, or more, lower than the air over the level portions of the field, a result of considerable practical importance in agriculture and horticulture.

The latent heat set free on the formation of dew appears from the observations clearly to retard the lowering of the temperature, but not to the extent which might have been expected. When, on the deposition of dew, the temperature of the air near the surface has fallen below $32^{\circ}$, as soon as the dew is congealed into hoar-frost the temperature of the lowest stratum of air in contact with the ground instantly rises to $32^{\circ}$; but at the same time the temperature of the air higher up steadily remains lower than $32^{\circ}$.

The absolute humidity of the air on clear nights on which no dew is deposited decreases from the ground upwards, just as happens during the day; but on the other hand, with dew, the humidity is least nearest the ground, and increases with the height, and this influence of dew, in diminishing the humidity, extends lupwards to at least twenty-two feet, the height to which the observations were carried. Since his observations clearly show that the absolute humidity begins in the evening to diminish near the ground before any dew is observed to be deposited, and also diminishes at all heights on those nights during which no dew whatever is formed, Dr. Hamberg is of opinion that the diminution of the humidity of the air during night is to be sought for in other physical causes than the deposition of dew.

Several of the points discussed will doubtless be made subjects of further investigation by others. In all cases it is most desirable, indeed absolutely necessary, to a critical valuation of the observations, that the authors give woodcuts and descriptions of the exact position and mode of protection adopted in the case of each thermometer employed in the observations. For such refined inquiries the method of observation must necessarily be a refined one ; in other words, such as will certainly secure the necessary comparability among all the instruments.

THE CHRONOMETERS OF SWITZERLAND

$W^{E}$ find in a recent number of the Bulletin of the Society of Natural Sciences at Neuchâtel an interesting report of the Neuchâtel Observatory on the annual competition of chronometers for prizes awarded yearly by the Observatory. The report gives some idea of the degree of perfection reached in Switzerland in the construction of chronometers. The 231 chronometers (four box and 227 pocket chronometers) admitted to the competition out of 270 sent in were submitted to a severe test, including changes of temperature and of position during periods of from two weeks to two months, and the results of the trial appear as follows. The average diurnal variations in the rates of the box-chronometers proved $0^{\circ} 32$ sec. (against $0^{\circ} 20$ in 1874 ), and of the pocleet ones 0.46 sec. (against 0.53 in 1874), and there was but two per cent. of these last, the average diurnal variation of which reached I sec. The various systems of escapements appeared, as was observed in former years, to have but little if any influence on the degree of precision of watches, provided they remain constantly in the same position, vertical or horizontal. The compensation for changes of temperature proved to bealtogether satisfactory, the average variation of 167 chronometers submitted to variations of temperature from I 5 to 25 Cent. degrees being but $0^{\prime} I 3$ sec. for each Centigrade degree. It must, however, be noticed that only 5 I per cent. of them showed variations below one-tenth of a second for each degree, and that to per cent. showed variations above $0^{\circ} 3 \mathrm{sec}$. Finally, the differences between the rates during the first and the last weeks were: for box-chronometers, 2 I I sec. 